\title{
A path forward for qualitative research on sustainability in the COVID-19 pandemic
}

\author{
Francisca N. Santana ${ }^{1}$. Courtney Hammond Wagner ${ }^{2,3}$ - Nina Berlin Rubin ${ }^{4} \cdot$ Laura S. P. Bloomfield $^{1}$ - Erica R. Bower ${ }^{1}$. \\ Stephanie L. Fischer ${ }^{4}$ Bianca S. Santos ${ }^{1} \cdot$ Gemma E. Smith ${ }^{1}$. Caroline T. Muraida ${ }^{1}$. Gabrielle Wong-Parodi ${ }^{3,4}$
}

Received: 25 June 2020 / Accepted: 3 December 2020 / Published online: 20 January 2021

(c) The Author(s), under exclusive licence to Springer Japan KK part of Springer Nature 2021

\begin{abstract}
The unique strengths of qualitative research, through in-depth inquiry and identification of unexpected themes and linkages, is essential to our growing understanding of COVID-19's impacts on the social world and its intersection with sustainability science. However, many challenges—physical, psychological, and ethical in nature-face qualitative researchers during the pandemic, as social distancing and travel restrictions prevent in-person field work. In this paper, we outline the essential contributions of qualitative study to sustainability science, discuss current challenges, and in turn, provide recommendations for researchers.
\end{abstract}

Keywords Qualitative methods · Virtual methods · Researcher well-being · Research ethics · Sustainability science · COVID-19

\section{Introduction}

Qualitative research is uniquely suited to examine meaningful experiences and perspectives during the COVID-19 pandemic - answering how and why the pandemic impacts our lives and society, and interpreting the significance of the pandemic for a sustainable future (Teti et al. 2020). The COVID-19 pandemic is unfolding unevenly across the globe; cases are dramatically increasing in some areas, and decreasing or stabilizing in others. Although treatments and vaccines are on the horizon, there are signs that COVID-19

Handled by Suneetha Subramanian, United Nations University Center Administration, India.

Gabrielle Wong-Parodi

gwongpar@stanford.edu

1 Emmett Interdisciplinary Program in Environment and Resources, Stanford University, 473 Via Ortega, Suite 226, Stanford, CA 94305-4210, USA

2 Water in the West, Stanford Woods Institute for the Environment, Stanford University, 473 Via Ortega, Stanford, CA 94305, USA

3 Stanford Woods Institute for the Environment, Stanford University, 473 Via Ortega, Stanford, CA 94305-4216, USA

4 Earth Systems Science, Stanford University, 473 Via Ortega, Rm. 140, Stanford, CA 94305-4216, USA may be with us for some time given the complexity of vaccine distribution and public suspicions about safety and effectiveness. This new reality will shape how qualitative research is conducted on topics related to sustainability science, defined here as the study of "the interactions between natural and social systems, and with how those interactions affect the challenge of sustainability: meeting the needs of present and future generations while substantially reducing poverty and conserving the planet's life support systems" (Kates 2011, p. 19,449). Yet, scholars who conduct qualitative and mixed methods research find themselves confronted with an important question: how can qualitative inquiry, founded on human connection, empathetic listening, and "thick description" (Geertz 1973), advance in a world of social distancing?

Despite its unique strengths, qualitative research has been notably absent from much of the uptick in COVID-19 social science research, perhaps because of the many challenges - physical, psychological and ethical-that the pandemic poses to conducting this type of research. In this comment, we first discuss how qualitative inquiry can deepen our understanding of the intersections of COVID-19 and sustainability issues. We then outline the major barriers to conducting qualitative research and offer recommendations for a path forward during the pandemic. 


\section{Contributions of qualitative research to sustainability science during COVID-19}

Qualitative research encompasses a diverse set of practices, contributing to sustainability science through (1) the collection and interpretation of in-depth data (Geertz 1973; Yin 2017), (2) generation of "grounded" theories of the social world (Glaser and Strauss 2017), (3) validation and triangulation of quantitative findings (Creswell and Clark 2017), and (4) empowerment of participants through participatory and community-engaged research (Cornwall and Jewkes 1995). As such, qualitative research may be conducted using different epistemological lenses and methods (Patton 2015). A commonality across these approaches is a field component, including, but not limited to, ethnography, participant observation, interviews, openended surveys/questionnaires, and focus groups.

Within sustainability science, qualitative studies provide insight into the lived experiences of individuals and communities facing dramatic environmental change, often detailing unexpected themes and connections. For instance, an interview-based study conducted by Dodd et al. (2018) on the effects of wildfire on Indigenous and non-Indigenous residents of Northwest Canada revealed how mental and physical health impacts such as fear and uncertainty compounded the direct health impacts of wildfire smoke exposure. In another study drawing on surveys, focus groups, and interviews, Airriess et al. (2008) uncovered how ties with a neighboring African American community supported evacuation, relocation, and recovery in a Vietnamese American community recovering from Hurricane Katrina. These two studies speak to the complexity of community experiences with environmental hazards, and tackle questions related to adaptation, recovery, and the future needs of community members in vulnerable areas, providing essential contributions to the field of sustainability science.

Since the start of the pandemic, there has been growing interest in studying its social impacts as scientists recognize intersections across fields, from public health to sustainability (Heymann and Shindo 2020; Van Bavel et al. 2020). For example, the pandemic amplifies existing environmental health and justice issues (Ferrante and Fearnside 2020; Wu et al. 2020; Yancy 2020; Laurencin and McClinton 2020) and may complicate transitions to low-carbon energy production such as the recent rollback of pollution regulations in the United States (Friedman 2020). It is imperative that qualitative inquiry include assessments of how the pandemic is changing human communities around the world and characterize emerging processes in response to COVID-19's social and economic disruptions. To address the interrelated physical, psychological, and ethical challenges of conducting sustainability science and qualitative research, we provide recommendations and resources to fellow researchers (see Table 1).

\section{Physical challenges}

COVID-19 social distancing protocols, shelter-in-place orders, and travel restrictions across the globe pose unique challenges to qualitative work, often grounded by the researcher's physical presence in communities. Although technology can facilitate virtual, qualitative data collection (i.e., telephone calls, online questionnaires, video-conferencing software), the inability to conduct in-person research may disproportionately affect access to geographically isolated or disadvantaged populations (Zhou et al. 2020; Marhefka et al. 2020), especially those who have been severely impacted by the pandemic (Tigue 2020). It may be more difficult to conduct research with communities with low computer literacy or lack of reliable communications technology (Irani 2019; Moyle et al. 2020). Limited in-person field work may also create barriers to gaining entrée and building trust with communities, particularly if the researcher is new to a region and does not have community partners or key informants (O'Connor and Madge 2003; Lo Iacono et al. 2016).

In addition to challenges of gaining access to new or disadvantaged communities, it may also be difficult to establish rapport with individual participants during an interview over virtual formats, even once access to the community has been granted. This is especially a concern if deeply personal issues related to grief or trauma are discussed ( $\mathrm{O}^{\prime}$ Connor and Madge 2003; Lo Iacono et al. 2016), or if the research topic assesses physical reactions or social cues (Seitz 2016). If researchers are unable to provide a physically private space for participants, it may also be challenging to protect confidentiality over virtual connections, creating additional barriers to research on sensitive topics (Marhefka et al. 2020). Although these physical challenges are significant, scholars can take steps to overcome them.

\section{Recommendations to address physical challenges}

During COVID-19, qualitative research design should account for the health hazards associated with in-person data collection and utilize virtual and participatory strategies when appropriate. To access isolated communities, we suggest researchers develop or draw on pre-existing collaborations with community partners, including local peoples and Indigenous groups in the study region (Bonevski et al. 2014). Investing in these community partnerships can 


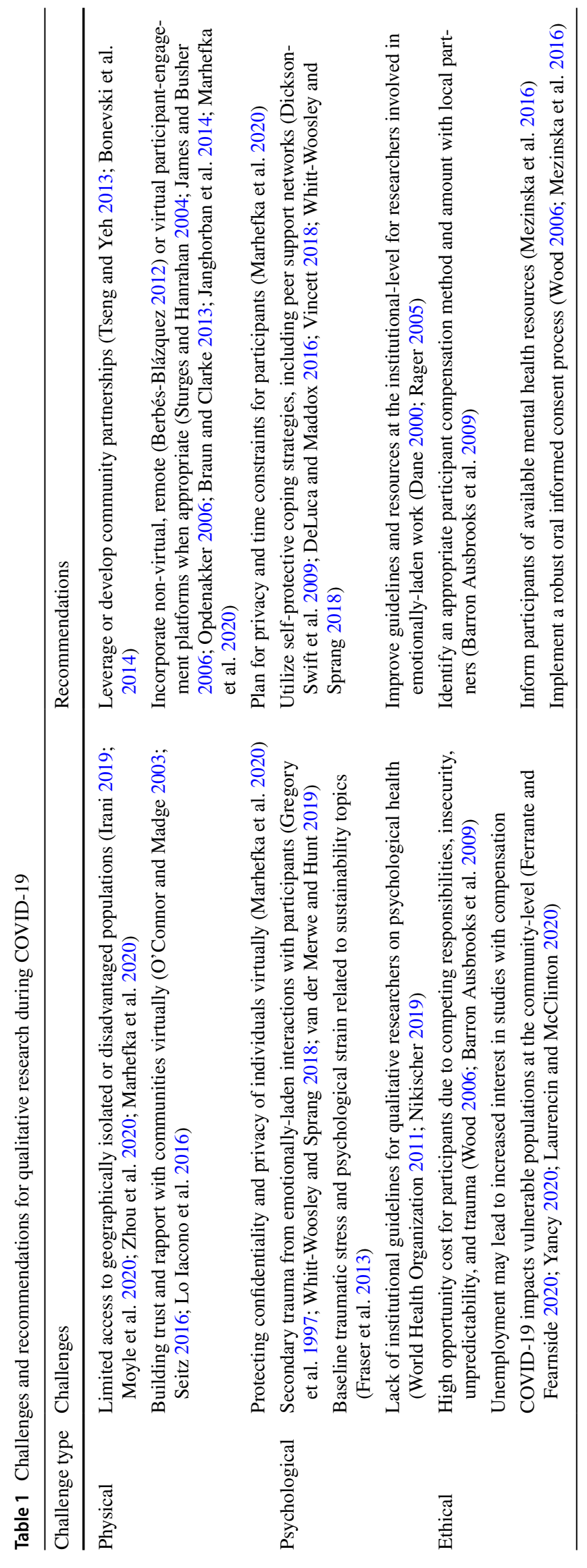


provide connections to remote populations during COVID19 (Tseng and Yeh 2013), while also deepening long-term trust between researchers and community members. Partnerships can also facilitate participatory data collection methods, such as photovoice or journaling, which provide opportunities for participants to document their lives, experiences, and changes in their communities at convenient times and in safe spaces without computer access (Berbés-Blázquez 2012). Specifically, photovoice is a qualitative method where community participants can use photography to record and engage with important issues where they live and work (Wang and Burris 2016). Participatory mapping is another method that can be employed to engage local peoples in the collection of diverse field data, from social interactions to biophysical indicators, and affirm "local people as knowledgeable actors" (Cornwall and Jewkes 1995, p. 1668). For example, in a study in Australia, Aboriginal and Indigenous peoples used participatory mapping to create water and vegetation environmental risk assessments, allowing for knowledge sharing not just between participants and researchers, but also between participant groups themselves (Robinson et al. 2016). Sustainability science is committed to the development of actionable knowledge (Kates 2011); participatory mapping and photovoice are just two of many participatory approaches that could be used to further this goal, even without researchers physically present.

When choosing to collect data virtually, qualitative researchers should consider the features of the platform, such as user-friendliness, host controls, session recording, and professionalism (Marhefka et al. 2020). For instance, video conferencing and screen-sharing are valuable tools to facilitate shared visual content usually available during in-person interviews (Janghorban et al. 2014). According to some scholars, telephone interviews do not yield significantly different results from in-person interviews (Sturges and Hanrahan 2004). Thus, telephone methods, along with email interviews or internet questionnaires, may be appropriate when visual cues are not essential, or if a large time difference exists between researcher and participant (James and Busher 2006; Opdenakker 2006; Braun and Clarke 2013).

Prior to data collection, researchers should practice with virtual techniques, assess participants' ability to communicate remotely, define what constitutes privacy, and if needed, arrange a private space for participants (James and Busher 2009; Marhefka et al. 2020). During virtual interviews, it is important to set participants at ease by acknowledging responses and providing encouragement, especially if audio or visual quality is poor (Braun and Clarke 2013). Further, researchers should be mindful of "Zoom fatigue" (i.e., feeling drained by video-conferencing) by scheduling breaks between participant conversations (Fosslien and Duffy 2020). Establishing rapport with individual participants virtually may require more lengthy, frequent communication compared to in-person field work; researchers should incorporate these considerations into timelines, while also balancing participant time constraints (James and Busher 2009).

\section{Psychological challenges}

Qualitative researchers and sustainability practitioners are not exempt from the psychological toll of the pandemic or the secondary stressors that may compound personal and professional trauma. Despite training to maintain scientific rigor by establishing professional boundaries and suppressing emotional reactions (Lalor et al. 2006), there is a growing literature on secondary trauma among social scientists. For example, many ethnographers work with marginalized or trauma-exposed individuals, leading to emotionally laden participant interactions (Whitt-Woosley and Sprang 2018; van der Merwe and Hunt 2019). Additionally, the iterative process of qualitative work-listening to, recording, and writing about participants' personal accounts of traumatic experiences-repeatedly exposes researchers to emotionally distressing content and may result in emotional transference, feelings of guilt, and frustration (Gregory et al. 1997). Thus, participant descriptions of the health, economic, and emotional effects of COVID-19, may intensify the emotional nature of the qualitative research experience for investigators.

Moreover, some studies have shown that as a group, sustainability researchers suffer from traumatic stress symptoms (i.e., constant worry, sadness, anxiety, and helplessness), and exhibit coping mechanisms of detachment (i.e., psychic numbing and emotional freezing) (Fraser et al. 2013). These symptoms have been attributed to the scale of sustainability issues, ongoing loss of ecosystems and species, and effects of climate change on human communities. Sustainability researchers may also be exposed to more secondary trauma during the pandemic because they often work with remote or resource-dependent communities. Recent reports have shown that remote, indigenous communities may be more vulnerable to COVID-19's impacts (Ferrante and Fearnside 2020), and deforestation and poaching may be on the rise in biodiverse, sensitive habitats due to decreased enforcement and loss of tourism, respectively (Maron 2020; Butler 2020).

Finally, international institutions and subjects ethics standards, such as the World Health Organization (WHO) and Institutional Review Boards (IRBs) do not address the psychological health of the researcher (World Health Organization 2011; Nikischer 2019). Given the psychological consequences inherent to the COVID-19 pandemic, and the lack of structural support, individual researchers must often assess risk and take precautions independently. 


\section{Recommendations to address psychological challenges}

Researchers should proactively consider their well-being when conducting qualitative work (Whitt-Woosley and Sprang 2018). Literature on secondary trauma provides recommendations for self-protective coping strategies for scholars conducting qualitative research during COVID19. These strategies include self-assessment by tracking psychologically taxing events, journaling or creative writing, physical health maintenance, meditation, and development of peer support networks (Dickson-Swift et al. 2009; Vincett 2018). In particular, establishing peer support networks for debriefing and reflecting on research experiences is an important component of secondary traumatic stress treatment (DeLuca and Maddox 2016).

Finally, lack of preparation and attention to researcher well-being may not only affect the individual, but also the quality of the research, providing an additional reason for improved training and institutional support (Rager 2005). Universities and relevant institutions should look to counseling, social work, and healthcare training programs for guidelines on self-care and support for individuals engaging in emotionally-laden research (Dane 2000).

\section{Ethical challenges}

The COVID-19 pandemic raises a number of ethical challenges for conducting qualitative sustainability research. We use the Belmont Report's three pillars of ethical research involving human subjects (respect for persons, beneficence, and justice) to explore ethical challenges and recent critiques that call for minimizing the aggregate harms to communities and increasing research transparency (Friesen et al. 2017).

With regard to respect for persons, study participants may be balancing multiple roles (i.e., professional, caretaker, educator) due to the pandemic, while grappling with health challenges, economic insecurity, and racial and ethnic inequities and injustice. Participating in a research study during the pandemic may impose a higher opportunity cost, made more stressful by the in-depth, often personal nature of qualitative research topics. Alternatively, individuals who have recently experienced a job loss may have an increased incentive to participate in research with compensation. The effects of the COVID-19 pandemic are not being shared equally across demographics; vulnerable populations, including Black, Indigenous, and Latinx communities, are facing higher COVID-19 infection rates and morbidity (Ferrante and Fearnside 2020; Yancy 2020;
Laurencin and McClinton 2020). Thus, the COVID19 pandemic challenges the standard IRB approach of addressing ethical issues for individual research participants (Wing 2002) and requires addressing ethical implications of research at the community-level, as the effects of the pandemic are wide-spread and interconnected.

Issues related to security, unpredictability, and recent trauma that apply to conflict zones and disaster settings also apply to considerations of beneficence and justice in qualitative research during the COVID-19 pandemic (Wood 2006; Barron Ausbrooks et al. 2009). Much like the challenges of working in communities post-disaster, it may be difficult to access participants, obtain informed free consent from vulnerable populations, and determine if compensation is merely an incentive or potentially coercive (Barron Ausbrooks et al. 2009). Also, while local partnerships are important for recruiting participants and conducting culturally sensitive research, we also acknowledge that these groups may be over-extended as a result of the pandemic.

\section{Recommendations to address ethical challenges}

To address these challenges, we suggest that sustainability researchers reexamine research using a holistic interpretation of the Belmont Report's three pillars (Friesen et al. 2017). To attend to the first principle "respect for persons and communities," Ryan et al. (1978), Friesen et al. (2017) we recommend that researchers conduct a thorough oral informed consent process that does not overstate expected benefits (Mezinska et al. 2016), and also provides participants with choices related to the disclosure of information and if it may be published or recorded (Wood 2006). This type of informed consent procedure and the autonomy offered to participants may contribute to decreased instances of retraumatization (Wood 2006). When working with distressed partners and organizations at the community-level, researchers should work to investigate questions and collect data of mutual interest. In line with the participatory action research tradition, this approach facilitates the pursuit of positive social change for the researcher and community members.

Additional strategies can support the principles of beneficence and justice. For example, researchers can inform participants of resources for psychological support and create a time lag between initial informed consent and research engagement (Mezinska et al. 2016). To address compensations and incentives, we propose consulting with local partners to identify reasonable compensation rates, ensuring that participants feel respected, but are not coerced by a high monetary value (Barron Ausbrooks et al. 2009). Also we echo the call to move from protection to participation of individuals from vulnerable populations (Friesen et al. 
2017). The uneven impacts of the pandemic across demographics demonstrate the importance of representing diverse experiences in qualitative research.

\section{Conclusion}

In this comment we have proposed creative, respectful recommendations to many of the challenges posed by the pandemic to qualitative research. We acknowledge that our recommendations may not provide tenable solutions for all research inquiries. In some cases, it may be necessary to postpone data collection, redesign research goals, and work within institutional guidelines to update research plans. However, a rich description of how the pandemic has changed our routines, relationships, and decision-making could provide the context needed to support culturally appropriate behavioral interventions (Van Bavel et al. 2020) and the foundation for policy interventions promoting sustainability. As we reflect on this new era, the value of collective action in tackling global sustainability challenges has never been more apparent. The insight that qualitative research can provide into interactions between social systems, ecosystems, and the impacts of COVID-19 will be crucial to solving the major issues within sustainability science in the next century.

\section{References}

Airriess CA, Li W, Leong KJ et al (2008) Church-based social capital, networks and geographical scale: Katrina evacuation, relocation, and recovery in a New Orleans Vietnamese American community. Geoforum 39:1333-1346. https://doi.org/10.1016/j.geofo rum.2007.11.003

Barron Ausbrooks CY, Barrett EJ, Martinez-Cosio M (2009) Ethical issues in disaster research: lessons from hurricane Katrina. Popul Res Policy Rev 28:93-106. https://doi.org/10.1007/s1111 3-008-9112-7

Berbés-Blázquez M (2012) A participatory assessment of ecosystem services and human wellbeing in rural costa rica using photovoice. Environ Manage 49:862-875. https://doi.org/10.1007/ s00267-012-9822-9

Bonevski B, Randell M, Paul C et al (2014) Reaching the hard-toreach: a systematic review of strategies for improving health and medical research with socially disadvantaged groups. BMC Med Res Methodol 14:42. https://doi.org/10.1186/1471-2288-14-42

Braun V, Clarke V (2013) Successful Qualitative Research: A Practical Guide for Beginners. SAGE, London

Butler RA (2020) Despite COVID, Amazon deforestation races higher. In: Mongabay Environ. News. https://news.mongabay. com/2020/04/despite-covid-amazon-deforestation-races-higher/. Accessed 21 Jun 2020

Cornwall A, Jewkes R (1995) What is participatory research? Soc Sci Med 41:1667-1676

Creswell JW, Clark VLP (2017) Designing and conducting mixed methods research. Sage Publications, Thousand Oaks, CA
Dane B (2000) Child welfare workers: an innovative approach for interacting with secondary trauma. J Soc Work Educ 36:27-38. https://doi.org/10.1080/10437797.2000.10778987

DeLuca JR, Maddox CB (2016) Tales from the ethnographic field: navigating feelings of guilt and privilege in the research process. Field Methods 28:284-299. https://doi.org/10.1177/15258 22X15611375

Dickson-Swift V, James EL, Kippen S, Liamputtong P (2009) Researching sensitive topics: qualitative research as emotion work. Qual Res 9:61-79. https://doi.org/10.1177/1468794108 098031

Dodd W, Scott P, Howard C et al (2018) Lived experience of a record wildfire season in the Northwest Territories, Canada. Can J Public Health 109:327-337. https://doi.org/10.17269/s4199 7-018-0070-5

Ferrante L, Fearnside PM (2020) Protect Indigenous peoples from COVID-19. Science 368:251.1-251. https://doi.org/10.1126/scien ce.abc0073

Fosslien L, Duffy MW (2020) How to combat zoom fatigue. Harv Bus Rev

Fraser J, Pantesco V, Plemons K et al (2013) Sustain Conserv Ecopsychol 5:70-79. https://doi.org/10.1089/eco.2012.0076

Friedman L (2020) E.P.A., Citing coronavirus, drastically relaxes rules for polluters. N.Y. Times, New York

Friesen P, Kearns L, Redman B, Caplan AL (2017) Rethinking the Belmont Report? Am J Bioeth 17:15-21. https://doi. org/10.1080/15265161.2017.1329482

Geertz C (1973) The interpretation of cultures. Basic books, New York

Glaser BG, Strauss AL (2017) Discovery of grounded theory: Strategies for qualitative research. Routledge, Abingdon

Gregory D, Russell CK, Phillips LR (1997) Beyond textual perfection: transcribers and vulnerable persons. Qual Health Res 7:294-300

Heymann DL, Shindo N (2020) COVID-19: what is next for public health? The Lancet 395:542-545. https://doi.org/10.1016/S0140 -6736(20)30374-3

Irani E (2019) The Use of videoconferencing for qualitative interviewing: opportunities, challenges, and considerations. Clin Nurs Res 28:3-8. https://doi.org/10.1177/1054773818803170

James N, Busher H (2006) Credibility, authenticity and voice: dilemmas in online interviewing. Qual Res 6:403-420. https://doi. org/10.1177/1468794106065010

James N, Busher H (2009) Online Interviewing. SAGE Publications, London

Janghorban R, Roudsari RL, Taghipour A (2014) Skype interviewing: The new generation of online synchronous interview in qualitative research. Int J Qual Stud Health Well-Being 9:24152. https://doi. org/10.3402/qhw.v9.24152

Kates RW (2011) What kind of a science is sustainability science? Proc Natl Acad Sci 108:19449-19450. https://doi.org/10.1073/ pnas. 1116097108

Lalor JG, Begley CM, Devane D (2006) Exploring painful experiences: impact of emotional narratives on members of a qualitative research team. J Adv Nurs 56:607-616. https://doi.org/10.11 11/j.1365-2648.2006.04039.x

Laurencin CT, McClinton A (2020) The COVID-19 pandemic: a call to action to identify and address racial and ethnic disparities. J Racial Ethn Health Disparities 7:398-402. https://doi.org/10.1007/s4061 5-020-00756-0

Lo Iacono V, Symonds P, Brown DHK (2016) Skype as a tool for qualitative research interviews. Sociol Res Online 21:103-117. https://doi.org/10.5153/sro.3952

Marhefka S, Lockhart E, Turner D (2020) Achieve research continuity during social distancing by rapidly implementing individual and group videoconferencing with participants: key considerations, best practices, and protocols. AIDS Behav. https://doi. org/10.1007/s10461-020-02837-x 
Maron DF (2020) Poaching threats loom as wildlife safaris put on hold due to COVID-19. In: Natl. Geogr. https://www.nationalgeograp hic.com/animals/2020/04/wildlife-safaris-halted-for-covid-boost -poaching-threat/. Accessed 21 Jun 2020

Mezinska S, Kakuk P, Mijaljica G et al (2016) Research in disaster settings: a systematic qualitative review of ethical guidelines. BMC Med Ethics 17:62. https://doi.org/10.1186/s12910-016-0148-7

Moyle W, Jones C, Murfield J, Liu F (2020) 'For me at 90, it's going to be difficult': feasibility of using iPad video-conferencing with older adults in long-term aged care. Aging Ment Health 24:349_ 352. https://doi.org/10.1080/13607863.2018.1525605

Nikischer A (2019) Vicarious trauma inside the academe: understanding the impact of teaching, researching and writing violence. High Educ 77:905-916. https://doi.org/10.1007/s10734-018-0308-4

O'Connor H, Madge C (2003) "Focus groups in cyberspace": using the Internet for qualitative research. Qual Mark Res Int J 6:133-143. https://doi.org/10.1108/13522750310470190

Opdenakker R (2006) Advantages and disadvantages of four interview techniques in qualitative research. Forum Qual Sozialforschung Forum Qual Soc Res. https://doi.org/10.17169/fqs-7.4.175

Patton MQ (2015) Qualitative research \& evaluation methods, 4th edn. Sage, Thousand Oaks, CA

Rager KB (2005) Compassion stress and the qualitative researcher. Qual Health Res 15:423-430. https://doi.org/10.1177/1049732304 272038

Robinson CJ, Maclean K, Hill R et al (2016) Participatory mapping to negotiate indigenous knowledge used to assess environmental risk. Sustain Sci 11:115-126. https://doi.org/10.1007/s1162 5-015-0292-x

Ryan KJ, Brady JV, Cooke RE, et al (1978) The Belmont Report: Ethical Principles and Guidelines for the Protection of Human Subjects of Research. The National Commission for the Protection of Human Subjects of Biomedical and Behavioral Research, Department of Health, Education, and Welfare

Seitz S (2016) Pixilated partnerships, overcoming obstacles in qualitative interviews via Skype: a research note. Qual Res 16:229-235. https://doi.org/10.1177/1468794115577011

Sturges JE, Hanrahan KJ (2004) Comparing telephone and face-to-face qualitative interviewing: a research note. Qual Res 4:107-118. https://doi.org/10.1177/1468794104041110

Teti M, Schatz E, Liebenberg L (2020) Methods in the time of COVID19: the vital role of qualitative inquiries. Int J Qual Methods 19:1609406920920962. https://doi.org/10.1177/1609406920 920962

Tigue K (2020) COVID-19 and climate change threats compound in minority communities. Sci Am
Tseng HW, Yeh H-T (2013) Team members' perceptions of online teamwork learning experiences and building teamwork trust: A qualitative study. Comput Educ 63:1-9. https://doi.org/10.1016/j. compedu.2012.11.013

Van Bavel JJ, Baicker K, Boggio PS et al (2020) Using social and behavioural science to support COVID-19 pandemic response. Nat Hum Behav. https://doi.org/10.1038/s41562-020-0884-z

van der Merwe A, Hunt X (2019) Secondary trauma among trauma researchers: lessons from the field. Psychol Trauma Theory Res Pract Policy 11:10-18. https://doi.org/10.1037/tra0000414

Vincett J (2018) Researcher self-care in organizational ethnography: Lessons from overcoming compassion fatigue. J Organ Ethnogr 7:44-58. https://doi.org/10.1108/JOE-09-2017-0041

Wang C, Burris MA (2016) Photovoice: Concept, Methodology, and Use for Participatory Needs Assessment. Health Educ Behav. https://doi.org/10.1177/109019819702400309

Whitt-Woosley A, Sprang G (2018) Secondary traumatic stress in social science researchers of trauma-exposed populations. J Aggress Maltreat Trauma 27:475-486. https://doi.org/10.1080/10926 771.2017 .1342109

Wing S (2002) Social responsibility and research ethics in communitydriven studies of industrialized hog production. Environ Health Perspect 110:437-444. https://doi.org/10.1289/ehp.02110437

Wood EJ (2006) The ethical challenges of field research in conflict zones. Qual Sociol 29:373-386. https://doi.org/10.1007/s1113 3-006-9027-8

World Health Organization (2011) Standards and operational guidance for ethics review of health-related research with human participants. WHO, Geneva

Wu X, Nethery RC, Sabath BM et al (2020) Exposure to air pollution and COVID-19 mortality in the United States: a nationwide cross-sectional study. medRxiv. https://doi. org/10.1101/2020.04.05.20054502

Yancy CW (2020) COVID-19 and African Americans. JAMA 323:1891-1892. https://doi.org/10.1001/jama.2020.6548

Yin RK (2017) Case study research and applications: Design and methods. SAGE Publications, Thousand Oaks, CA

Zhou X, Snoswell CL, Harding LE et al (2020) The Role of telehealth in reducing the mental health burden from COVID-19. Telemed E-Health 26:377-379. https://doi.org/10.1089/tmj.2020.0068

Publisher's Note Springer Nature remains neutral with regard to jurisdictional claims in published maps and institutional affiliations. 